\section{REFERENCES}

1. Saito R, Hotta F. Congenital pericardial defect associated with cardiac incarceration: case report. Am Heart J 1980;100:866-70.

2. Ellis $\mathrm{K}$, Leeds NE, Himmelstein A. Congenital deficiencies in parietal pericardium: a review of two new cases including successful diagnosis by plain roentgenography. Am J Roentgenol 1959;82:125-37.

3. Southworth $\mathrm{H}$, Stevenson CS. Congenital defects of the pericardium. Arch Intern Med 1938;61:223-9.

4. Pernot C, Hoeffel JC, Frisch HR, Brauer B. Partial left pericardial defect with herniation of the left atrial appendage. Thorax 1972;27:246-50.

5. Robin E, Ganguli SN, Fowler MS. Strangulation of the left atrial appendage through a congenital partial pericardial defect. Chest 1975;67:354-5.

6. Altman CA, Ettedgui JA, Wozney P, Beerman LB. Noninvasive diagnostic features of partial absence of the pericardium. Am J Cardiol 1989;63:1536-7.

7. Glancy DL, Sanders CV, Porta A. Posterior chest wall pulsation in congenital complete absence of the left pericardium. Chest 1974;65:564-6.

8. Kansal S, Roitman D, Sheffield LT. Two-dimensional echocardiography of congenital absence of pericardium. Am Heart J 1985;109:912-5.

9. Schiavone WA, O'Donnell JK. Congenital absence of the left portion of parietal pericardium demonstrated by nuclear magnetic resonance imaging. Am J Cardiol 1985;55:1439-40.

10. Glover LB, Barcia A, Reeves TJ. Congenital absence of the pericardium: a review of the literature with demonstration of a previously unreported fluoroscopic finding. Am J Roentgenol 1969;106:542-9.

11. Nasser WK, Helman C, Tavel ME, Feigenbaum H, Fisch C. Congenital absence of the left pericardium: clinical, electrocardiographic, radiographic, hemodynamic and angiographic findings in six cases. Circulation 1970;41:469-78.

12. Burrows PE, Smallhorn JS, Trusler GA, Daneman A, Moes CAF, Rowe RD. Partial absence of the left parietal pericardium with herniation of the left atrial appendage: diagnosis by cross-sectional echocardiography and contrast-enhanced computed tomography. Pediatr Cardiol 1987;8:205-8.

\title{
INTENTIONAL DELAYED REPAIR OF ACUTE DISSECTION OF THE ASCENDING AORTA COMPLICATED BY STROKE
}

\author{
William Piccione, Jr., MD, Ian N. Hamilton, MD, and Hassan Najafi, MD, Chicago, Ill.
}

It is generally accepted that patients with acute dissection of the ascending aorta require urgent surgical reconstruction. However, the optimal treatment of patients with acute ascending aortic dissection complicated by stroke remains controversial. ${ }^{1}$ The group at Stanford has suggested that stroke does not negate urgent surgical intervention, whereas others consider stroke a relative, if not absolute, contraindication to surgery.

We report the case of a 42-year-old man with phenotypic features of Marina's syndrome who was taken to a suburban hospital with anterior chest pain and an acute left hemispheric cerebrovascular accident manifested by right hemiplegia and dysarthria. Magnetic resonance

From the Department of Cardiovascular Thoracic Surgery, Rush-Presbyterian-St. Luke's Medical Center, Chicago, Ill.

J ThoraC CARDIOVASC Surg 1995;109:807-8

Copyright (C) 1995 by Mosby-Year Book, Inc.

$0022-5223 / 95 \$ 3.00+0 \quad \mathbf{1 2 / 8 / 6 1 4 8 2}$ scanning confirmed the presence of an ischemic left hemispheric infarct. Carotid noninvasive assessment demonstrated thrombosis of the right carotid artery along with an intimal flap in the left carotid artery. Computed tomography and magnetic resonance scanning confirmed the presence of an ascending aortic dissection involving the arch with extension into the brachiocephalic vessels (Fig. 1). The patient was transferred to our facility for emergency surgery.

On arrival in our institution the patient had a dense left hemispheric deficit with dysarthria, flaccid paralysis of the right leg, and severe weakness of the right arm. He was in hemodynamically stable condition with no right carotid pulse and mild aortic insufficiency by echocardiogram. The electrocardiogram showed no abnormalities.

Because of the patient's severe neurologic insult and hemodynamic stability, we elected to delay surgical intervention. He was treated with antihypertensive drugs and $\beta$-adrenergic blockade. He subsequently underwent physical therapy, with a marked recovery of motor function. 


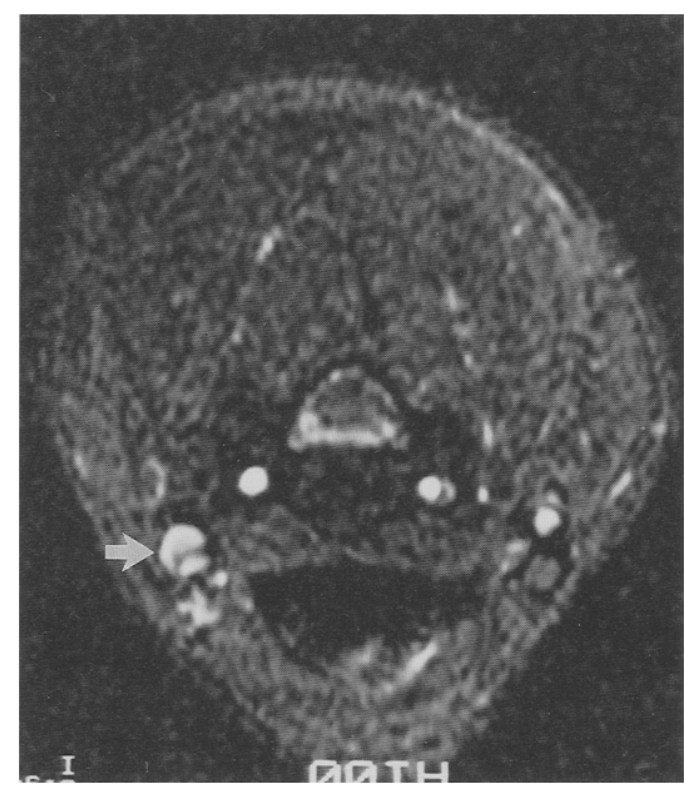

Fig. 1. Magnetic resonance scan at the level of C-5 demonstrating an intimal flap in the left carotid artery (arrow).

Approximately 5 weeks after the initial event, the patient was readmitted for surgery. His neurologic status had reached a plateau with near total recovery of right arm and leg function. The patient subsequently underwent aortic root reconstruction with a valved conduit and reimplantation of the coronary arteries in the Bentall fashion. Standard cardiopulmonary bypass was used with cannulation of the right atrium and left femoral arteries. Moderate hypothermia was used to $28^{\circ} \mathrm{C}$. Myocardial protection was achieved with cold blood cardioplegic solution, delivered initially antegrade with subsequent retrograde delivery. Distally, true and false lumina were reapproximated into the suture line at the level of the innominate artery. Postoperatively the patient did well with no deterioration in neurologic function, and he was discharged to his home on the eighth postoperative day.

Clearly most patients with acute ascending aortic dissection should undergo urgent surgical reconstruction. Dissection complicated by stroke represents a more formidable challenge. Fann and colleagues ${ }^{1}$ reported on seven patients with acute aortic dissection complicated by stroke. All underwent urgent surgical reconstruction. Three patients (43\%) had persistent severe neurologic deficits with resultant death within 4 months. One patient
(14\%) had partial neurologic recovery and the remaining three $(43 \%)$ had major resolution of neurologic function. Any delay in surgery logically imposes further risk of retrograde dissection with aortic valve and coronary involvement and subsequent death. In the setting of hemodynamic stability, the optimal period to delay such a significant procedure remains unclear.

Surgical procedures involving cardiopulmonary bypass and possibly hypothermic circulatory arrest may severely adversely affect neurologic recovery in the setting of an acute cerebrovascular accident. Cerebral edema after an ischemic infarct is maximal between 1 and 3 days. However, blood-brain barrier function does not become normal for 7 to 10 days. During this period fluctuations in blood pressure may be extremely detrimental. ${ }^{2}$ In addition, acute reperfusion of ischemic brain tissue may also reduce the threshold for hemorrhage into an infarct. ${ }^{3}$ Clinical studies have suggested that carotid artery surgery can be undertaken after acute stroke with no increase in morbidity or mortality, so long as the operation is delayed until neurologic recovery has reached a plateau. ${ }^{3}$

Intentionally delaying aortic surgery in selected patients is not a novel concept. Akins and associates ${ }^{4}$ have previously reported delaying surgery in patients with traumatic aortic disruption complicated by extensive central nervous system injury, extensive burns, or contaminated wounds. Surgery was postponed in 14 such patients and they were treated medically with antihypertensive drugs and $\beta$-adrenergic blockade. Surgery was eventually undertaken with a $14 \%$ mortality.

Our patient had a dramatic neurologic recovery before the operation and had no further insult at the time of the operation. This experience might further support delaying surgery in hemodynamically stable patients with acute ascending aortic dissection complicated by stroke until neurologic function has reached a clinical plateau.

\section{REFERENCES}

1. Fann J, Sarris G, Miller D, et al. Surgical management of acute aortic dissection complicated by stroke. Circulation 1989;80(Suppl):I257-63.

2. O'Brien MD. Ischemic cerebral edema: a review. Stroke 1979;10:623-8.

3. Piotrowski J, Bernhard V, Rubin J, et al. Timing of carotid endarterectomy after acute stroke. J Vasc Surg 1990;11:45-52.

4. Akins CW, Buckley MJ, Daggett W, McIlduff J, Austen G. Acute traumatic disruption of the thoracic aorta: a ten year experience. Ann Thorac Surg 1981;31:305-9. 